\title{
A trans-response effect of partial reinforcement
}

W. W. WENRICH, G. E. ECKMAN, M. J. MOORE AND D. F. HOUSTON

ROANOKE COLLEGE

Eight rats were conditioned to run an L-maze with food pellets as reinforcement. Reinforcement was available to the control $S$ s at the end of the maze on every trial, while the experimental $S s$ were reinforced on an intermittent schedule. Following this differential training in the maze, all Ss were placed in a Skinner box and conditioned to press a bar for food which succeeded each response. After the bar press response was established, all Ss were run to a $3 \mathrm{~min}$ extinction criterion. During the extinction session the experimental Ss emitted more responses than the control Ss, and these results suggest that at least one effect of partial reinforcement, resistance to extinction, may be evidenced across unrelated responses.

Increased resistance to extinction is one of the more dramatic effects of the partial or intermittent reinforcement of a response (PRE). That this effect is relatively stable is concluded in studies by Jenkins (1962), Thelos (1962), and Sutherland, Mackintosh, \& Wolfe (1965). These investigations indicated that PRE can be sustained through a block of continuously reinforced training trials. Additional information regarding the stabillty of PRE was given in an experiment by Ross (1964) which showed that PRE can not only be sustained through continuous relnforcement, but also through changed response. In the portion of Ross' experiment pertinent to the present Investigation, the Se were first conditioned on either an intermittent or a continuous schedule for jumping $5-1 / 2 \mathrm{ln}$. from a start box to a goal box. Later the so were conditioned to traverse a long runway, and were then given 32 extinction trials in the runway. If was found that the partially reinforced Ss were more resistant to extinction as measured by the latencles in the extinction trials. While this study did offer evidence that PRE may be observed over a changed response, It does not answer the question of whether or not the effect may be carried over to a "new" and unrelated response, since It could be argued that the running and jumping responses required of the So in Ross' study have rather similar topographies and are closely related parts of a rat's behavioral repertoire. The present study was designed to test the hypothesis that PRE will be reflected in a new response, a repponce unrelated to the behavior on which the partial relnforcement schedule was estabiliched.

\section{Subjects}

Eight naive male albino rate, approximately 70 days old at the Initiation of the experiment, were used. Throughout the experiment the se were mu after $10 \mathrm{~h}$ of lood deprivation. Immedintely following each dally session the si were permitted to free feed for $3 \mathrm{~h}$ in their bome cages.

\section{Apparatus}

The training apparatus was an $L$ maze 36 in. long, 4-1/2 in. wide, and 6-1/2 in. high. One end of this maze served as the Ss' starting position, and the other end served as the entrance to the goal box. The goal box, which formed the $L$ part of the maze, was set at a 90 degree angle to the main arm of the maze. In dimension it was 12 in. long, 4-1/2 in. wide, and $6-1 / 2$ in. high. The test apparatus was a Scientific Prototype Model A-105 Rodent Test Cage (a skinner box) in conjunction with standard recording and timing devices.

Procedure

On the first 17 days of the experiment each $S$ was given 40 trials per day in the $L$ maze. A trial consisted of placing the $S$ in the start position of the maze and allowing $S$ to run the length of the maze into the goal box. Throughout the 17 days of training the control Ss were reinforced on every trial with two $45 \mathrm{mg}$ Noyes food pellets. The experimental Ss were also placed on a continuous schedule of reinforcement during the first three days of $\mathrm{L}$ maze training, but were thereafter run on a partial reinforcement schedule. Beginning with the fourth day, experimental $\mathrm{Ss}$ were always reinforced on the first five trials and the last trial of each dally session. Their maze running on Trials 6 through 39 was maintained on an intermittent schedule of reinforcement which was gradually increased on each succeeding session unthl it was stabllized at FR 15 on Days 15, 16, and 17. The major training portion of this study was completed after Session 17.

On Day 18 the Se were conditioned to press the bar of the Bkinner box. All Ss were on a continuous schedule of reinforcement, and each was relnforced $145 \mathrm{mg}$ Noyes food pellets) for 50 bar presses. On Day 19 all Ss were again placed in the Skinner box for an additional 25 relnforced bar presses. The following day (test day) each $S$ was first given 10 trials in the I maze. As before, the control Ss were relnforced on each trial, whlle the experimental Ss were reinforced only on the first and tenth trials. After this phase of the test day was completed, each $S$ was put into the sidiner box and reinforced for the firat 15 bar presses. Immediately following the 15 reiniorced reaponses the food magazine was made inoperative, and each $\mathbf{S}$ was $\mathrm{rm}$ to an extinction criterion of three consecutive mimutes without a response.

\section{hesutis and Discussion.}

Table 1 presents the total number of responses made by each 8 during the extinction period of the teet day. A review of the data of this table shows that 
Table 1 Total number of bar presses emitted during the extinction period of the test day

\begin{tabular}{cccc}
\hline $\begin{array}{c}\text { Experimental } \\
\text { Subjects }\end{array}$ & $\begin{array}{c}\text { Number of } \\
\text { Responses }\end{array}$ & $\begin{array}{c}\text { Control } \\
\text { Subjects }\end{array}$ & $\begin{array}{c}\text { Number of } \\
\text { Responses }\end{array}$ \\
\hline E1 & 174 & C1 & 98 \\
E2 & 165 & C2 & 93 \\
E3 & 95 & C3 & 70 \\
E4 & 300 & C4 & 139 \\
\hline Totals & 734 & & 400
\end{tabular}

the experimental Ss were more resistant to extinction than the controls, and that this behavior was not only observed in the general trend of the data, but was also manifest in the performance of the individual Ss. In order to determine the probability that the results of this experiment may have occurred by chance, the Mann-Whitney $U$ test was applied to the data, and a $p=.057$ was obtained. Since the probability that attends a chance occurrence of the data is only .057 , it seems reasonable to state that the results of the experiment do offer support for the empirical hypothesis. It does appear that at least one effect of partial reinforcement; increased resistance to extinction, may be observed in a new response, a response unrelated to the behavior on which the partial reinforcement schedule was established. It is felt that the practical and systematic importance of this phenomenon is worthy of further research.

\section{References}

JENKINS, H. M. Resistance to extinction when partial reinforcement is followed by regular reinforcement. J. exp. Psychol., 1962, 64, 441-450.

ROSS, R. Positive and negative partial-reinforcement extinction effects carried through continuous reinforcement, changed motivation and changed drive. J. exp. Psychol, 1964, 68, 492-502.

SUTHERLAND, N. S., MACKINTOSH, N. J., \& WOLFE, J. B. Extinction as a function of the order of partial and consistent reinforcement. J. exp. Psychol., 1965, 69, 56-59.

THEIOS, J. The partial reinforcement effect sustained through blocks of continuous reinforcement. J. exp. Psychol, 1962, 64, 1-6. 